\title{
Decomposition of carbon emissions from industrial energy activities in China
}

\author{
Zhonglin Shenga, Weida He, Yufei Xin \\ University of Science and Technology Beijing, Beijing, P.R.China
}

Keywords: energy consumption, carbon emissions, index decomposition, China industry, economic growth

\begin{abstract}
Energy system is the largest source of carbon emissions in a country or region. Since China' s economic increases rapidly these years, it also brings the growth of energy consumption and carbon emissions. This paper indicates an index decomposition analysis to evaluate the carbon emissions from industrial energy activities of China. From the results, we can conclude that the economic growth cycle fluctuation and the increase of industrial production is the major reason for the rapid increase in carbon emissions.
\end{abstract}

\section{Introduction}

Carbon emissions or energy consumption decomposition of factors has been a hot issue of international energy research since the $1980 \mathrm{~s}^{[1]}$. The index decomposition analysis is the widely accepted method in the development of energy and environmental policy around the world ${ }^{[2]}$. We can dive different methods into three kinds, Laspeyres exponent method, simple average decomposition method and adaptive weight decomposition method. Laspeyres index is proposed by the German E.Laspeyres in 1864 which is based on the number of index weight as the weighted composite index to measure the same factors in the fixed base period ${ }^{[3]}$. Many scholars have used this method to study the energy consumption of the United States and some other OECD countries ${ }^{[4][5][6]}$. Later in the developing countries, some scholars have applied the Laspeyres index to do research on energy issues. Simple average decomposition method commonly uses simple average and the corresponding parameter at the end of one year as factor weights. They proposed decomposition method to make use of the beginning years and late energy consumption average values as weights, and calculate the corresponding factors of the increment with the logarithmic method ${ }^{[7]}$. The decomposition method adopts the simple arithmetic mean of the corresponding parameters of two years as the weight of the factor $^{[8]}$. South Korean scholars proposed the MRCI(mean rate-of-change index $)^{[9]}$. To determine the weighting is to to introduce all the coefficients of the average growth rate of average value as the important component of the weighting factor, allowing the existence of a free residual value, and it it important that this method is different from the LMDI, allowing data to be negative $\mathrm{e}^{[10]}$.

${ }^{a}$ Corresponding author: sheng075071@hotmail.com 
Table 1 Carbon increment of different forms of decomposition method

\begin{tabular}{|c|c|c|c|}
\hline Methods & Output variables $/ \Delta E_{p d n}$ & Structure variables $/ \Delta E_{s t r}$ & Intensity variables $/ \Delta E_{\text {int }}$ \\
\hline Laspeyres & $\sum_{i} Y_{T} S_{i, 0} I_{i, 0}-E_{0}$ & $\sum_{i} Y_{0} S_{i, T} I_{i, 0}-E_{0}$ & $\sum_{i} Y_{0} S_{i, 0} I_{i, \mathrm{~T}}-E_{0}$ \\
\hline SAD1 & $0.5 \sum_{i}\left(E_{i, T}+E_{i, 0}\right) \ln \left(Y_{T} / Y_{0}\right)$ & $0.5 \sum_{i}\left(E_{i, T}+E_{i, 0}\right) \ln \left(S_{i, T} / \mathrm{S}_{\mathrm{i}, 0}\right)$ & $0.5 \sum_{i}\left(E_{i, T}+E_{i, 0}\right) \ln \left(I_{i, T} / I_{i, 0}\right)$ \\
\hline SAD2 & $0.5\left(I_{0}+I_{T}\right)\left(Y_{T}-Y_{0}\right)$ & $0.5 \sum_{i}\left(I_{i, 0} Y_{0}+I_{i, T} Y_{T}\right)\left(S_{i, T}-S_{i, 0}\right)$ & $0.5 \sum_{i}\left(S_{i, 0} Y_{0}+S_{i, T} Y_{T}\right)\left(I_{i, T}-I_{i, 0}\right)$ \\
\hline LMDI & $\sum_{i} L\left(E_{i, T}, E_{i, 0}\right) \ln \left(Y_{T} / \mathrm{Y}_{0}\right)$ & $\sum_{i} L\left(E_{i, T}, E_{i, 0}\right) \ln \left(S_{i, T} / \mathrm{S}_{\mathrm{i}, 0}\right)$ & $\sum_{i} L\left(E_{i, T}, E_{i, 0}\right) \ln \left(I_{i, T} / \mathrm{I}_{\mathrm{i}, 0}\right)$ \\
\hline MIRCI & $\sum_{i j} M_{i j}(*)(1 / \bar{y})\left(y_{i}-y_{0}\right)$ & $\sum_{i j} M_{i j}(*)\left(1 / \overline{S_{j}}\right)\left(S_{i, T}-S_{i, 0}\right)$ & $\sum_{i j} M_{i j}(*)\left(1 / \bar{I}_{j}\right)\left(I_{i, T}-I_{i, 0}\right)$ \\
\hline
\end{tabular}

According to Laspeyres index method and above different method of SAD thoughts, we can set the total output value, the strength of the industrial structure and the energy consumption caused by the increase of energy consumption respectively showed in the Table 1, including SAD1 and SAD2.

\section{Methods}

Carbon emissions intensity or energy consumption intensity is used in the most researches of carbon decomposition. In many studies, they think this factor plays an absolutely important role in energy consumption growth. On the basis of previous studies, this study combines with carbon emission calculation and input-output table, through further decomposition of carbon emissions, and we divide the carbon emissions resulting from industrial combustion energy into six factors, the total energy consumption, energy consumption structure, technical factors, intermediate inputs, the output value of industry structure and the total industrial output value. With the LMDI analysis method, this paper analyzes the influence of industrial combustion energy leading to carbon emissions.

According to the detailed steps of the carbon emission calculation proposed by IPCC ${ }^{[11]}$, combining with the input-output table, the formula of carbon emission in a country or region is expressed as the following.

$$
E_{A}=\sum Q_{A} * e_{j} * n_{j} *\left(1 / m_{j}\right) * y_{j} * P_{A}
$$

EA is the total amount of carbon emissions in the A year. QA is the total energy consumption. ej

$$
\text { represents equivalent carbon emission coefficient of the industry } \mathrm{j} \text {, and } e_{j}=\sum_{i} f_{i} * c_{j i} \text {. nj represents }
$$
the proportion of industrial intermediate inputs, namely $n_{j}=\sum_{k} a_{k j}$. mj represents the total amount of intermediate inputs industry $\mathrm{j}$. yj is the output of industry $\mathrm{j}$ accounted for the proportion of industrial output, that is, the structure of industry production value. PA is the industrial output. Based on LMDI method, carbon increment can be expressed as:

$$
\begin{aligned}
& \Delta E_{t o t}=E_{T}-E_{0}=\Delta E_{q}+\Delta E_{e}+\Delta E_{n}+\Delta E_{m}+\Delta E_{y}+\Delta E_{p} \\
& =\sum_{j} L\left(E_{j, T}, E_{j, 0}\right) \ln \left(Q_{T} / \mathrm{Q}_{0}\right)+\sum_{j} L\left(E_{j, T}, E_{j, 0}\right) \ln \left(e_{j, T} / e_{j, 0}\right) \\
& +\sum_{j} L\left(E_{j, T}, E_{j, 0}\right) \ln \left(n_{j, T} / n_{j, 0}\right)+\sum_{j} L\left(E_{j, T}, E_{j, 0}\right) \ln \left(m_{j, 0} / m_{j, T}\right) \\
& +\sum_{j} L\left(E_{j, T}, E_{j, 0}\right) \ln \left(y_{j, r} / \mathrm{y}_{\mathrm{j}, 0}\right)+\sum_{j} L\left(E_{j, T}, E_{j, 0}\right) \ln \left(P_{T} / P_{0}\right)
\end{aligned}
$$


represents the increment caused by the total energy consumption and is the increment caused by the energy consumption structure. is the increment caused by technological factors and is for the increment cause by intermediate input, while represents the increment caused by the output value structure, and is for the increment caused by total production.

$$
L\left(E_{j, T}, E_{j, 0}\right)=\left(E_{j, T}-E_{j, 0}\right) / \ln \left(E_{j, T} / E_{j, 0}\right)
$$

As the data involves two aspects of energy consumption and input-output, this paper selects 1997-2002,2002-2005,2005-2008 these three time periods of historical data to calculate. The data mainly comes from China Energy Statistical Yearbook, China Input-output Tables and the corresponding statistical yearbook.

\section{Conclusion}

According to the above calculation, we can know that economic growth cycle fluctuation and the increase of industrial production is a major cause of the rapid increase of carbon emissions. Besides, one of important factors in the increase of carbon emissions is that the efficiency of energy use becomes not obvious. If the total amount of energy consumption is increased with the increase of total production, the energy consumption per unit output value is less obvious. The overall energy structure has not been greatly improved is the fundamental reason for the rapid increase in carbon emissions. Due to a large difference in carbon emission coefficient of various energy sources, especially water and electricity, nuclear power, wind energy, biomass energy and other clean energy, the coefficient of carbon emission is almost zero. Therefore, the radical change of the energy structure can fundamentally change the total amount of carbon emission in a country or region.

\section{References}

[1]Ang B. W.,Less S. Y. 1994. Decomposition of industrial energy consumption: some methodological and application issues. Energy Economics,16(2):83-92.

[2]Ang B.W., Zhang F.Q and Choi K.H. 1998. Factorizing changes in energy and environmental indicators through decomposition. Energy,23(6):489-495.

[3]Boyd G.A., Hanson D.A. and Sterner T. 1988. Decomposition of changes in energy intensity-A comparison of the divisia index and other methods. Energy Economics,10(4):309-312.

[4]Chung H.S, Rhee H.C. 2001. A residual-free decomposition of the sources of carbon dioxide emissions: a case of the Korean industries. Energy,26:15-30.

[5]Baron, R., Aasrud, A., Sinton, J.,Campbell,N., Jiang, K. Zhuang, X.,2012. Policy options for lowcarbon power generation in China: Designing an emissions trading system for China's electricity sector, International Energy Agency,8:33-49.

[6]Boyd,O.2012. China's energy reform and climate policy: the ideas motivating change, CCEP Working Paper no.1205, Center for climate economics and policy, Crawford School of Public Policy, The Australian National University.

[7]Jotzo, F., 2013. Emissions Trading in China: Principles, Design Options and Lessons from International Practice, CCEP Working Paper no. 1303, Centre for Climate Economics and Policy, Crawford School of Public Policy, The Australian National

University, Canberra.

[8]International Energy Agency (IEA), 2013b. World Energy Outlook 2013, Paris: International Energy Agency.

[9]Kim, Y.G., Lim,J.S.2014. Emissions trading scheme design for power industries facing price regulation. Energy Policy,75:84-90.

[10]Jiang, J.J., Ye, B., Ma, X.M., 2014. The construction of Shenzhen's carbon emission trading scheme. Energy Policy, 75:17-21.

[11]International Energy Agency (IEA), 2013a. CO2 Emissions Indicators 2013, Paris: International Energy Agency. 